\title{
PHYSICOCHEMICAL RESEARCH OF CLINICALLY RETRIEVED CU-NI-TI ORTHODONTIC ARCHWIRES
}

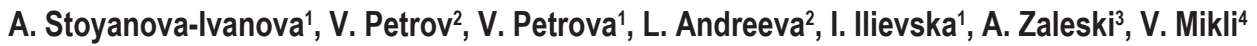 \\ ${ }^{1}$ Institute of Solid State Physics, BAS - Sofia, Bulgaria \\ ${ }^{2}$ Faculty of Dental Medicine, Medical University - Sofia, Bulgaria \\ ${ }^{3}$ Institute of Low Temperatures and Structure Research, PAS - Wroclaw, Poland \\ ${ }^{4}$ Institute of Materials and Environmental Technology, Tallinn University of Technology - Tallinn, Estonia
}

\begin{abstract}
In modern orthodontics, thermally activated archwires are used more widely in clinical practice, because they have unique properties like superelasticity and biocompatibility. The aim of the present study was to characterize commercial $35^{\circ} \mathrm{C} \mathrm{Cu}$ $\mathrm{NiTi}$ archwires in terms of their phase transition behavior, chemical composition, surface topography properties after clinical usage, as well as the influence of the autoclaving process. Materials and methods. $35^{\circ} \mathrm{C}$ Thermo-Active Copper NiTi (CuNiTi) of ORMCO, Glendora, CA, USA (as-received, as-received autoclaved and clinically retrieved) with rectangular cross-section and dimension $0.016 \times 0.022$ inch, were investigated. The physicochemical research was conducted via Differential Scanning Calorimetry (DSC), Scanning Electron Microscopy (SEM), Energy Dispersive Spectroscopy (EDX) and Xray Diffraction Analysis (XRD). The autoclaving was done in Runyes model $B$ autoclave. Results. The DSC results revealed the austenite start $\left(9.8^{\circ} \mathrm{C} ; 26.47^{\circ} \mathrm{C}\right)$ and austenite finish $\left(28^{\circ} \mathrm{C} ; 31.74^{\circ} \mathrm{C}\right)$ temperatures for the as-received and autoclaved archwires respectively. For clinically retrieved samples the austenite finish temperature (Af) is around $27^{\circ} \mathrm{C}$. The XRD patterns of the as-received and clinically retrieved samples show almost identical diffraction patterns. Rough surface of the CuNiTi alloy was revealed by the SEM analysis. Autoclaving process seems to have no effects on archwires' structure and chemical composition. Chemical content of the investigated as-received CuNiTi are Ni, Ti and $\mathrm{Cu}: 47.07 \mathrm{wt} \%$ and $46.81 \mathrm{wt} \%$ and $6.11 \mathrm{wt} \%$, respectively. The autoclaving process seems to have little influence on the transition temperature. The results from our study showed little difference $\left(\sim 7^{\circ} \mathrm{C}\right)$ in the finish transition temperatures (Af), compared to the manufacturer's claim. No intermediate $R$ phase was detected by DSC. Conclusion. A good knowledge of the structural changes that occur in CuNiTi alloys in the oral cavity is useful for the orthodontists in order to optimize orthodontic treatment.
\end{abstract}

Key words: $35^{\circ} \mathrm{C}$ Thermo-Active Copper NiTi (CuNiTi), Autoclaving process, DSC, XRD, SEM, EDX

Corresponding author: Angelina Stoyanova-Ivanova, Institute of Solid State Physics, BAS, 72 Tzarigradsko Chaussee Blvd., Bg-1784 Sofia, E-mail: aksi_bg@abv.bg, angelina@issp.bas.bg

ACCEPTED: 15 December 2019 


\section{INTRODUCTION}

T he thermoactivated NiTi alloys are introduced for use in orthodontics by ORMCO in 1994 and are classified as active martensitic alloys that feature thermally induced memory effect. The shape memory effect is characterized by the ability of the material to return to its original shape by heating the material above the transition temperature. The NiTi alloy's transition temperature from martensite to austenite occurs near the temperature of the oral cavity [1]. The transition between these two phases/structures is fully reversible, occurs at low temperatures and it takes place rapidly over some temperature transformation range (TTR). An intermediate phase, termed R-phase from its rhombohedral atomic arrangement, can form during the forward (heating) transformation from martensite to austenite and the reverse (cooling) transformation from austenite to martensite [2]. These different phases are responsible for two clinically significant properties of nickel-titanium: shape memory and superelasticity [3].

When the practitioner takes the wire at $25^{\circ} \mathrm{C}$ (room temperature) its modulus of elasticity is $44.9 \mathrm{GPa}$, but in the oral cavity, at $34^{\circ} \mathrm{C}$, the modulus becomes $58.6 \mathrm{GPa}$. When the patient drinks hot coffee at $60^{\circ} \mathrm{C}$, the modulus raises to $63.6 \mathrm{GPa}$ [4]. Different elasticity allows the orthodontist to insert the archwire easier into the bracket slot of the misaligned teeth, since the archwire is in martensitic phase. These features of the CuNiTi archwires are very useful in the initial stages of treatment with fixed appliances. Many orthodontic companies claim that manufacturing process of coppernickel-titanium gives the opportunity for production of archwires with more consistent transition temperatures, allowing the orthodontist to customize treatment to various patients based on the force level needed [5]. Some studies have shown that CuNiTi archwires with different transformation temperatures are marketed to provide differing force levels depending upon the temperature of the oral environment [5]. However, other studies showed no difference between as-received and clinically retrieved wires, except for a significant reduction in the heating enthalpy associated with the martensite to austenite transition in the $27^{\circ} \mathrm{C}$ and 35 ${ }^{\circ} \mathrm{C}$ CuNiTi archwires [6]. The clinically relevant benefits of CuNiTi over NiTi wires include more constant force generation over longer activation spans, greater resistance to permanent deformation, more stable superelasticity characteristics when cyclically loaded, better spring-back and less hysteresis [7]. Brantley et all [8] speculated that some transformation in NiTi based wires may not be completely reversible on atomic level, possibly leading to structural defects and decreased clinical performance.

ORMCO's archwires are available at different temperature variants of $27^{\circ} \mathrm{C}, 35^{\circ} \mathrm{C}$, and $40^{\circ} \mathrm{C}$, corresponding to their austenite finish temperatures (Af) for the completion of the martensite to austenite phase transformation [9]. Recent studies for $\mathrm{Cu}$ $\mathrm{NiTi}$ archwires [10] (ORMCO, Glendora, CA, USA) claim that the archwires are in fully austenite phase in room temperature and with elemental composition as follows: $48.75 \mathrm{wt} \%$ nickel, $45.18 \mathrm{wt} \%$ titanium, $5.51 \mathrm{wt} \%$ copper and presence of $0.23 \mathrm{wt} \%$ chromium. Other studies show that $35^{\circ} \mathrm{C}$ CuNiTi wires are martensitic at room temperature $\left(21^{\circ} \mathrm{C}\right)$ and change into austenite when warmed in the oral environment $\left(37^{\circ} \mathrm{C}\right)$ [6]. Moore et al [9] found that usually the temperature in the oral cavity is in the range of $33^{\circ} \mathrm{C}$ to $37^{\circ} \mathrm{C}$ for $79 \%$ of the time the archwire is in the mouth. They also state that $20 \%$ of the time, the temperature is lower than the average in the oral cavity $35^{\circ} \mathrm{C}$ and higher at $1 \%$ of the cases. Before placing the wire in the patient's mouth, some clinicians are using autoclaving process on the archwires so they can avoid infections in order to provide safety for their patients [5]. Autoclaving is a process of sterilizing materials and instruments with water vapor under pressure, which is done in appliances called autoclaves. Studies on the effect of autoclaving process on orthodontic wires have been going on since the 1980's and it is believed that this process can influence the properties of the orthodontic wires. There is a study from 2019 that investigated thermally activated $\mathrm{NiTi}$ archwires from different manufacturers, some of which are ORMCO's as-received, clinically used and clinically used sterilized CuNiTi wires. Those archwires have been studied only by DSC and the results did not show large variations in their transition temperature range [11]. The results are in contradiction with one another. Some of the studies report mechanical alterations, whereas others defend the opposite [12].

The aim of this study is to characterize commercial $35^{\circ} \mathrm{C}$ Thermo-Active Copper NiTi archwires (asreceived, as-received autoclaved and clinically retrieved) in terms of their thermal behavior, chemical composition, surface topography properties and the influence of autoclaving process. 


\section{MATERIALS AND METHODS}

Orthodontic CuNiTi archwires (ORMCO Glendora, CA, USA) from the same box (there are 10 packages in one box), provided from distributor, with transition temperature Af at $35^{\circ} \mathrm{C}$ were examined at the areas corresponding to premolars. The experimental samples are with dimensions $(0.016 \times 0.022$ inch) and rectangular cross-section. The investigations were conducted on as-received and clinically retrieved archwires as well as on one as-received archwire, gone through an autoclaving process.

In the beginning, the archwires are removed from the package and then placed in the patient's mouth. These wires were not previously autoclaved. The surface of the clinically retrieved archwires is initially treated with oxygen water and then with $70 \%$ ethyl alcohol. All patients were treated in the practice of researchers at the Department of Orthodontics in Sofia, Bulgaria.

Each sample was weighed before the analysis. The Differential Scanning Calorimetry (DSC) analyses were performed on a Perkin-Elmer DSC model P-E 8000. For each individual test, before introducing the sample in the DSC apparatus, a calibration with indium was made. The reference chamber and each wire specimen were scanned at the temperature range from $-50^{\circ} \mathrm{C}$ to $+50^{\circ} \mathrm{C}$ (apparatus temperature range: from $-170^{\circ} \mathrm{C}$ to $+600^{\circ} \mathrm{C}$ ) for both the heating and cooling processes, at $10^{\circ} \mathrm{C} / \mathrm{min}$. The DSC plots were qualitatively and quantitatively analyzed by the DSC manufacturer's software. Onset and Endset temperatures of the martensitic and austenitic phases were derived from the graphs produced by the software according to standard transition temperature determination methods.

The crystalline structure was studied at room temperature by a Bruker D8 Advance powder diffractometer with a Cu-Ka target radiation at $40 \mathrm{kV}$ and $20 \mathrm{~mA}$, with a LynxEye Detector, within the range from $5-80^{\circ}$ $2 \theta$ at a constant $\operatorname{step} 0.02^{\circ} 2 \theta$.

The surface morphology of the orthodontic archwires was studied by a Zeiss scanning electron microscope, model EVO MA-15 with LaB6 cathode. The accelerating voltage range of the apparatus used for the tests is from 0.2 to $30 \mathrm{kV}$. The research was conducted at $20 \mathrm{kV}$. The elemental composition of the samples was analysed by Energy Dispersive X-ray Spectroscopy (EDX) with Bruker Esprit 1.8 system at $20 \mathrm{kV}$ accelerating voltage. The relative error of the analysis in determining the elemental composition percentage by weight is $0.8 \%$.

The program in which examined archwires were autoclaved is $121^{\circ} \mathrm{C}$ and a pressure of $1-1,3$ bar. The full automatic cycle lasts about 60 minutes and includes heating, three-stage vacuum air extraction, sterilization and drying. Prior to autoclaving, the orthodontic arcwires are packaged in a special foil for sterilization. The Runyes model B autoclave, model: Steam sterilizer SEA-12L-B, manufactured by Ningbo Runyes Medical Instrument Co., Ltd., HK, with threestage vacuum airflow from the chamber and vacuum drying was used.

\section{RESULTS}

The transformation temperatures were determined by a thermal test (DSC). Table 1 lists the DSC results for the heating and cooling processes respectively, for CuNiTi archwires (as-received, asreceived autoclaved and clinically retrieved) with a commercially $\mathrm{Af}$ of $35^{\circ} \mathrm{C}$. Also listed in the table is the duration of clinical usage for the clinically retrieved archwires, standard deviation heating onset temperature (As, Ms), finish temperature (Af, Mf) and enthalpy for transformation in CuNiTi archwires tested. In Figure 1, the curves of the heating/ cooling process can be observed. The results for the heating process show different Af temperatures for all of the samples, but all of them do not go up to $35^{\circ} \mathrm{C}$. The cooling curves for all samples were similar, with very small peaks. The Af of the archwires before and after the clinical use varies insignificantly $\left(\sim 1^{\circ} \mathrm{C}\right)$.

Information about the presence or absence of the martensitic and austenitic phases is received by XRD analyses of the investigated orthodontic wires (Figure 2). The XRD analysis of the as-received, as-received autoclaved and used up to 6 and more than 8 weeks orthodontic archwires was made at room temperature. The diffraction patterns show typical peaks for Ni-Ti alloy with austenite structure. The austenitic phase has an ordered base-centered cubic structure, which occurs at high temperature. The as-received and as-received autoclaved samples show almost identical diffraction pattern with a maximum at $42.42^{\circ}$ (austenite phase).

The SEM images (Fig. 3-6) of the surface topography revealed rough surface with many pores on all of the investigated CuNiTi archwires. 
Table 1. DSC results for heating/cooling process of the investigated CuNiTi archwires

\begin{tabular}{|c|c|c|c|c|c|c|}
\hline Wire & \multirow{2}{*}{$\begin{array}{c}\text { Wire } \\
\text { Segment }\end{array}$} & \multicolumn{5}{|c|}{ Heating process } \\
\hline \multirow{11}{*}{ CuNiTi } & & Mass (mg) & As $\left({ }^{\circ} \mathrm{C}\right)$ & Peak $\left({ }^{\circ} \mathrm{C}\right)$ & $\operatorname{Af}\left({ }^{\circ} \mathrm{C}\right)$ & Enthalpy $(\mathrm{J} / \mathrm{g})$ \\
\hline & As-received & 5.045 & 9.80 & 20.60 & 28.00 & 10.9548 \\
\hline & As-received autoclaved & 6.023 & 26.47 & 27.62 & 31.74 & 17.0411 \\
\hline & Up to 6 weeks & 12.146 & 9.43 & 22.81 & 27.24 & 15.8621 \\
\hline & More than 8 weeks & 4.115 & 12.91 & 21.79 & 27.02 & 8.2641 \\
\hline & Wire & \multicolumn{5}{|c|}{ Cooling process } \\
\hline & Segment & Mass (mg) & $\operatorname{Ms}\left({ }^{\circ} \mathrm{C}\right)$ & Peak $\left({ }^{\circ} \mathrm{C}\right)$ & $\operatorname{Mf}\left({ }^{\circ} \mathrm{C}\right)$ & Enthalpy $(\mathrm{J} / \mathrm{g})$ \\
\hline & As-received & 5.045 & 10.13 & -1.10 & -12.66 & -12.6908 \\
\hline & As-received autoclaved & 6.023 & 12.01 & 2.40 & -4.76 & -13.6155 \\
\hline & Up to 6 weeks & 12.146 & 15.81 & 1.46 & -7.67 & -7.8784 \\
\hline & More than 8 weeks & 4.115 & 10.71 & -0.20 & -11.42 & -13.4704 \\
\hline
\end{tabular}
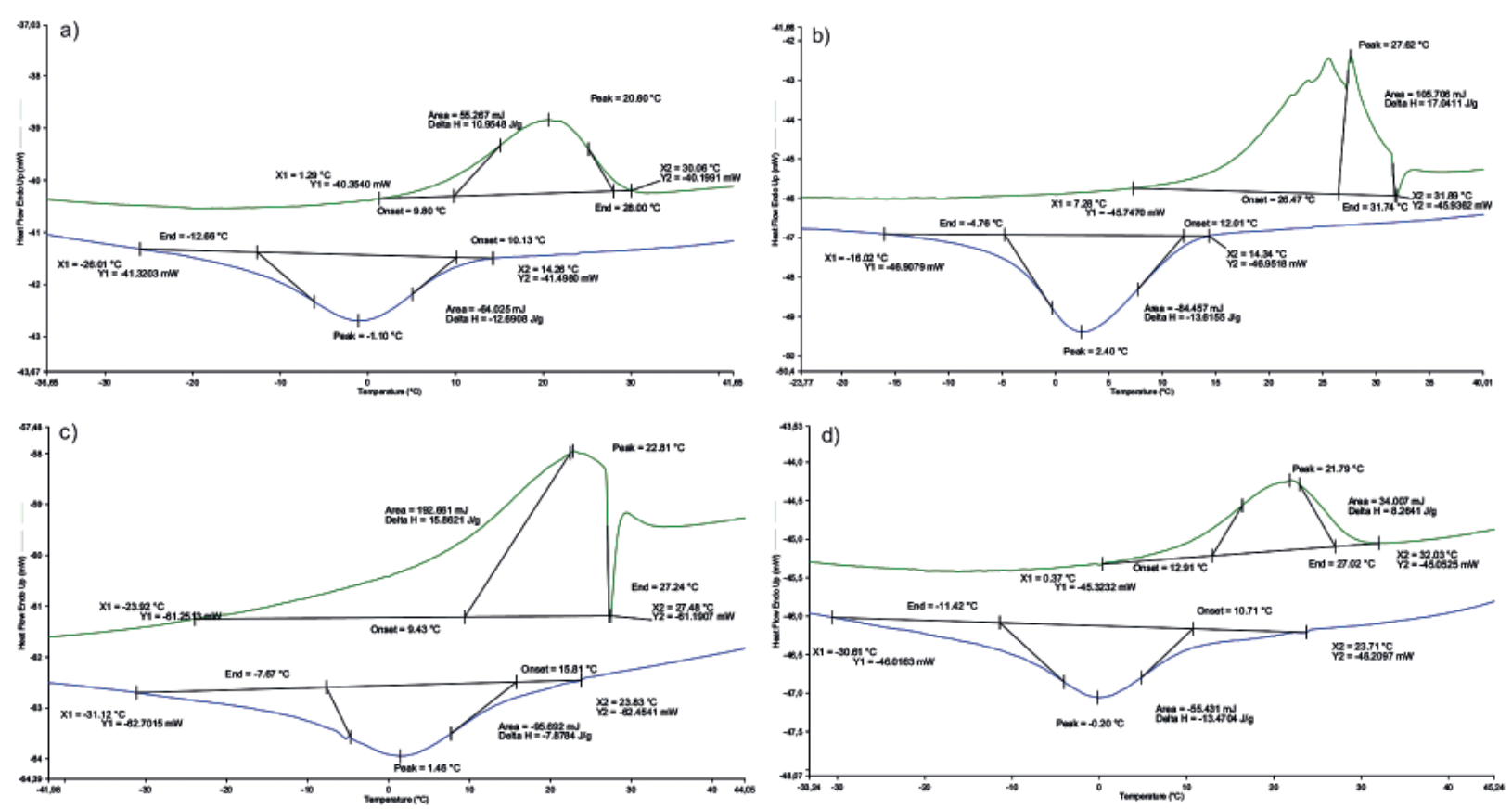

Fig. 1. DSC heating/cooling curves for the investigated: a) as-received, b) as-received autoclaved, c) used up to 6 weeks and d) used more than 8 weeks CuNiTi archwires

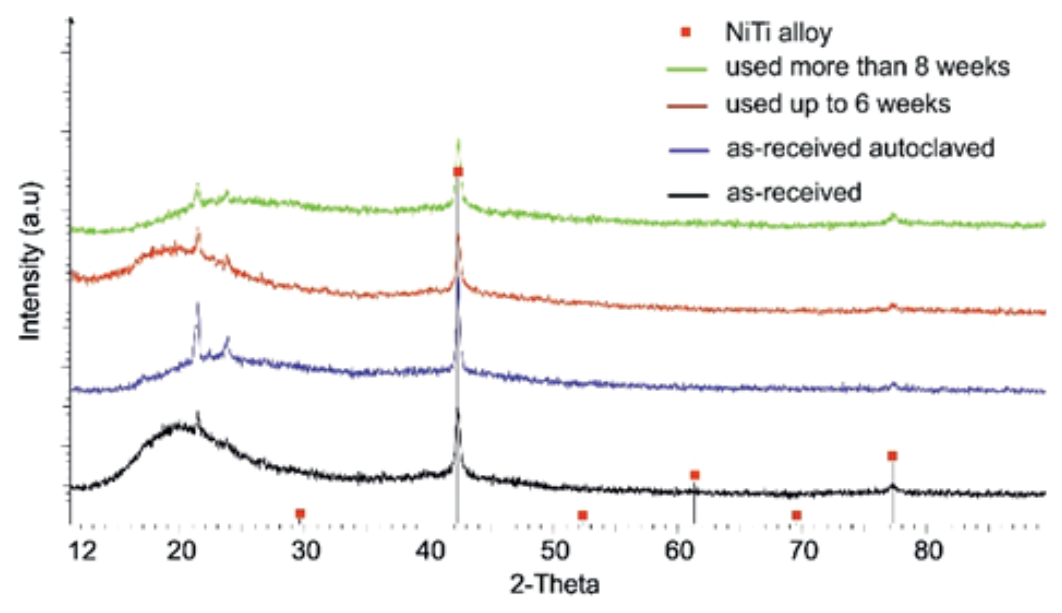

Fig. 2. XRD patterns of the investigated CuNiTi archwires 

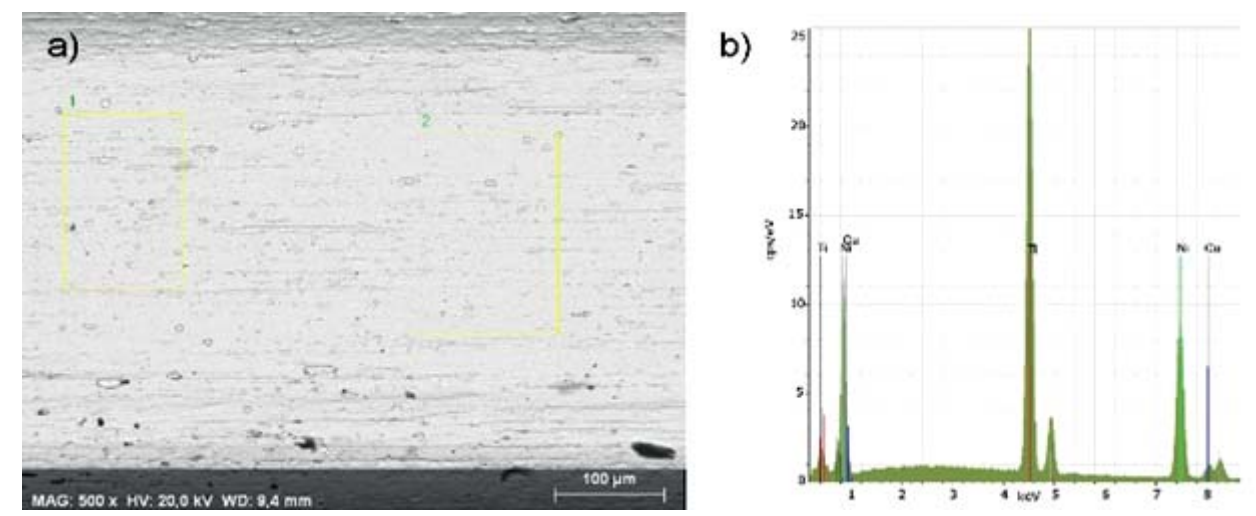

Fig. 3. a) SEM micrograph ( $x$ 500) and b) EDX spectra of one area of as-received CUNiTi heat-activated orthodontic archwire
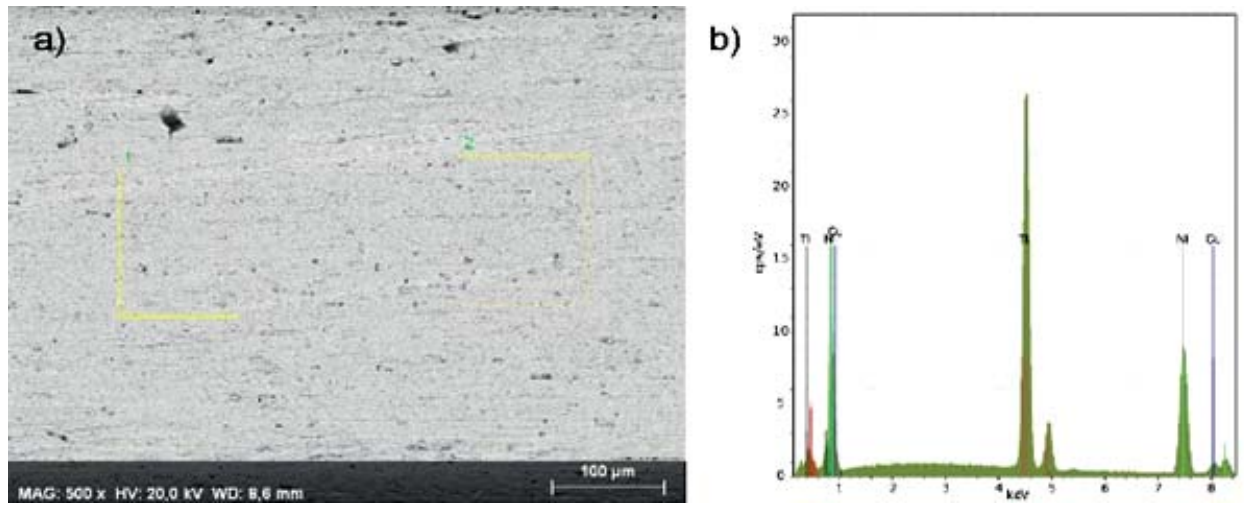

Fig. 4. a) SEM micrograph (x 500) and b) EDX spectra of one area of as-received autoclaved CuNiTi heat-activated orthodontic archwire
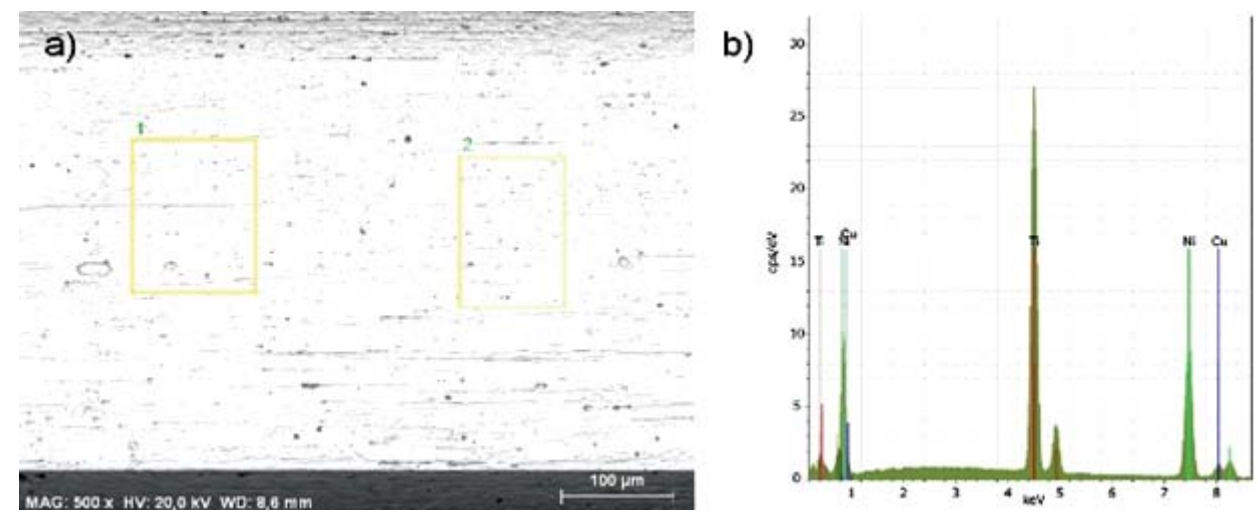

Fig. 5. a) SEM micrograph ( $\times 500$ ) and b) EDX spectra of one area of used up to 6 weeks CuNiTi heat-activated orthodontic archwire
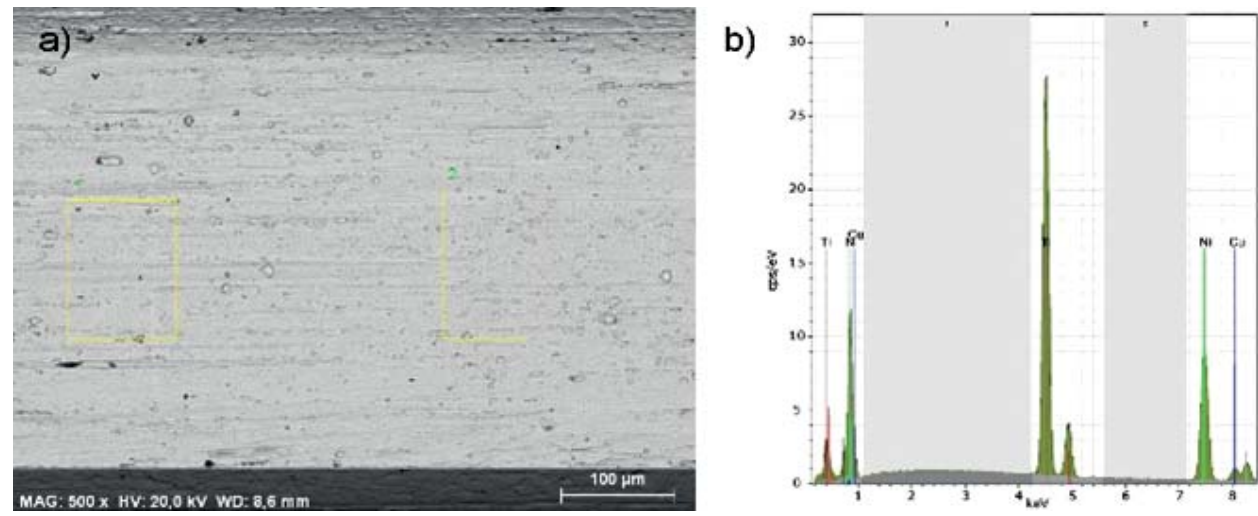

Fig. 6. a) SEM micrograph (x 500) and b) EDX spectra of one area of used more than 8 weeks CuNiTi heat-activated orthodontic archwire 
The EDX spectras (Fig. 3-6) and the averaged results for the elemental composition (Table 2) of all studied archwires are shown. The results show that there are only minimal variations in the chemical composition of the as-received, autoclaved and clinically retrieved CuNiTi archwires.

\section{DISCUSSION}

The clinical purpose of the new generation thermoactive archwires is to provide optimal force appropriate for the first stage of orthodontic treatment. Temperature transitions from martensite to austenite leads to reversible or irreversible changes in the alloys, which are expected to be useful for tooth movement. By these archwires the movement of the teeth is gradually accomplished within the biologically tolerable range. In this way, the patient's comfort is combined with sufficient force to move teeth or teeth segments into the desired position during the treatment. Orthodontic CuNiTi archwires (ORMCO Glendora, CA): as-received, as-received autoclaved and clinically retrieved from the same package, with variable advertised $\mathrm{Af}\left(35^{\circ} \mathrm{C}\right)$, were examined at the areas corresponding to premolars.

There are thermal studies of as-received CuNiTi ORMCO archwires that show Af $\sim 32.2^{\circ} \mathrm{C}[6,13]$. Matthew et al [12] studies on as-received and clinically retrieved CuNiTi archwires showed differences within approximately $\sim 2^{\circ} \mathrm{C}$ of the manufacturer's claim. Our DSC results revealed on as-received $\mathrm{Af}=28^{\circ}$ $\mathrm{C}$ and for as-received autoclaved $31.74^{\circ} \mathrm{C}$. For the clinically retrieved Af is around $\sim 27^{\circ} \mathrm{C}$. The results are with temperature differences $\left(\sim 7^{\circ} \mathrm{C}\right)$ from what the manufacturer claimed. From this information it was assumed that the manufacturing differences amongst the variants is what caused the changes in Af. Joshua et al [6] observe presence of $R$ phase upon heating and no $\mathrm{R}$ phase present upon cooling on as-received $35^{\circ} \mathrm{C} \mathrm{CuNiTi}$ archwires. In our studies on the investigated archwires there is no presence of $R$ phase upon heating and cooling.
The amount of force could be easily adjusted by the changes in the transition temperature range. For example, a thermoactive archwire with a transition temperature of $27^{\circ} \mathrm{C}$ placed in the patient's mouth releases heavier forces than an archwire with a transition temperature of $40^{\circ} \mathrm{C}$. The first one turns to the austenitic phase in the mouth but the second is in martensitic phase because the transition temperature is not reached [1].

Due to the expressed interest of Bulgarian orthodontists, our research is conducted in order to improve the knowledge about the effect of autoclaving process on the archwires.

From the XRD analysis on the autoclaved archwire, a sharp peak can be observed, which indicates a better crystallite. Autoclaving process seems to have no effects on archwires' structure. After clinical usage there is an additional phase, which is probably formed on the surface of the archwires. Bigger pores are observed on the surface of the clinically retrieved orthodontic archwires due to the aggressive oral environment during treatment and masticatory function. Our results for the chemical composition of the asreceived $35^{\circ} \mathrm{C}$ CuNiTi archwire from ORMCO show $\mathrm{Cu} 6.11 \mathrm{wt} \%$, and for $\mathrm{Ni}$ and $\mathrm{Ti}: 47.07 \mathrm{wt} \%$ and 46.81 wt $\%$, respectively, which differs from the results of Helge et all [14], whose study of the same wire shows that $\mathrm{Cu}$ weight percentage is $6.9 \mathrm{wt} \%$, and for $\mathrm{Ni}$ and $\mathrm{Ti}$ are $50.7 \mathrm{wt} \%$ and $42.4 \mathrm{wt} \%$, respectively. In other words, the archwire investigated by us contains less $\mathrm{Ni}$. During the clinical use of the archwires in the patient's mouth, the elemental composition does not change significantly.

\section{CONCLUSIONS}

Commercially available $35^{\circ} \mathrm{C}$ Thermo-active Copper $\mathrm{NiTi}$ archwires (as-received, as-received autoclaved and clinically retrieved) with rectangular cross-section were investigated. The DSC analysis of the studied $35^{\circ} \mathrm{C}$ CuNiTi archwires showed transition temperatures that differ with approximately $\sim 7^{\circ} \mathrm{C}$ from the

Table 2. Elemental content of the investigated $35^{\circ} \mathrm{C}$ CuNiTi archwires

\begin{tabular}{|c|c|c|c|c|c|}
\hline Cu-Ni-Ti archwires & & & nts, We & & \\
\hline Spectrum & $\mathrm{Ti}$ & $\mathrm{Ni}$ & $\mathrm{Cu}$ & Error & Total \\
\hline As-received & 46.81 & 47.07 & 6.11 & $+/-0.8 \%$ & 100.00 \\
\hline As-received autoclaved & 46.03 & 47.85 & 6.10 & $+/-0.8 \%$ & 100.00 \\
\hline Used up to 6 weeks & 45.68 & 47.96 & 6.35 & $+/-0.8 \%$ & 100.00 \\
\hline Used more than 8 weeks & 47.25 & 46.61 & 6.14 & $+/-0.8 \%$ & 100.00 \\
\hline
\end{tabular}


commercially provided one. Also, no intermediate $R$ phase was detected with the DSC. The XRD diffraction patterns show typical peaks for $\mathrm{Ni}$-Ti alloy with austenite structure. The surface topography showed rough surface with scratches and porosities. The chemical content of the investigated as-received $\mathrm{Cu}$ $\mathrm{NiTi}$ is $\mathrm{Cu}, \mathrm{Ni}$ and Ti: $6.11 \mathrm{wt} \%, 47.07 \mathrm{wt} \%$ and 46.81 wt $\%$, respectively. The autoclaving process has no influence on the chemical composition. Intraoral usage duration of the orthodontic archwires has no significant effect on the chemical content. The analysis confirms the presence only of the main elemental components of the alloy.

A good knowledge of the structural changes that occur in CuNiTi alloys in the oral cavity is useful for the orthodontists in order to optimize orthodontic treatment.

Acknowledgments: This work was a part of a bilateral project between the Bulgarian Academy of Sciences and Estonian Academy of Science, Tallinn University of Technology (Estonian projects TK 141 IUT 19-28) and Bulgarian Academy of Sciences and Institute of Low Temperature and Structure Research, Polish Academy of Sciences.

Disclosure summary: The authors have nothing to disclose.

\section{REFERENCES}

1. Kusy RP. A review of contemporary archwires: their properties and characteristics. Angle Orthod, 1997, 67:197-208.

2. Shaw JA, Churchill CB, ladicola MA, Callister WD. Tips and tricks for characterizing shape memory alloy wire: Part 1-Dif- ferential scanning calorimetry and basic phenomena. Mat Sci and Eng, 2008, 55-62.

3. Miura F, Mogi M, Ohura Y, Hamanaka H. The super-elastic property of the Japanese NiTi alloy wire for use in orthodontics. Am J Orthod, 1986, 90:1-10.

4. Kusy RP, Whitley JQ. Thermal and mechanical characteristics of stainless steel, titanium-molybdenum, and nickeltitanium archwires. Am J Orthod Dentofacial Orthop, 2007, 131: 229-37.

5. Rosen MA. Mechanical Properties of Copper-Nickel-Titanium Archwires. Marquette University: Master thesis, 2016.

6. Gilbert J. Thermal Properties of Copper Nickel-Titanium Orthodontic Archwires. Marquette University: Master thesis, 2016.

7. Petrov V. Investigation of the chemical composition and structure of orthodontic archwires before and after treatment, Medical University - Sofia. 2014.

8. Brantley WA, Eliades T. Orthodontic materials: scientific and clinical aspects. J of Ortho, 2001, 29(1):77-103.

9. Moore RJ, Watts JT, Hood JA, Burritt DJ. Intra-oral temperature variation over 24 hours. Eur J Orthod, 1999, 3:249-61.

10. Ilievska I, Petrov V, Andreeva L et al. Structural and morphological characterization of heat-activated nickel-titanium archwires, Bul Chem Commun, 2017, 49(A):33-39.

11. Vieira BS, Cançado RH, Freitas KMS et al. Effect of Clinical Use and Sterilization Process on the Transition Temperature Range of Thermally NiTi Alloys. The Open Dentistry Journal, 2019, 13:261-266.

12. Biermann MC, Berzins DW, Bradley TG. Thermal Analysis of As-received and Clinically Retrieved Copper-nickel-titanium Orthodontic Archwires, The angle orthod, 2007, 3:499-503.

13. Reynolds P, Georgios K. Interlot variations of transition temperature range and force delivery in copper-nickel-titaniumorthodontic wires. Am J of Orthod and Dent Orthop, 2014, 146:215-226.

14. Fischer-Brandies H, Es-Souni M, Kock N et al. Transformation Behavior, Chemical Composition, Surface Topography and Bending Properties of Five Selected 0.016" x 0.022" NiTi archwires. J Orofac Orthop, 2003, 2:88-99. 